\title{
Plate and Screws Fixation Idea to Preserve Metacarpal Length in Comminuted Fractures
}

\section{ISSN: 2576-8875}

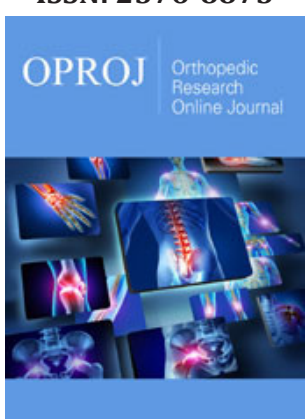

${ }^{* 1}$ Corresponding author: Ahmed Mokhtar Mahmoud Elbayer, Hamad Medical Corporation, Doha

Submission: 監 May 13, 2019

Published: May 16, 2019

Volume 5 - Issue 4

How to cite this article: Ahmed M M E, Habib Al-Basti, Iqbal W, Sohail Q Sara M M. Plate and Screws Fixation Idea to Preserve Metacarpal Length in Comminuted Fractures. Ortho Res Online J. 5(4). OPROJ.000618.2019.

DOI: 10.31031/OPROJ.2019.05.000618

Copyright@: Ahmed Mokhtar Mahmoud Elbayer, This article is distributed under the terms of the Creative Commons Attribution 4.0 International License, which permits unrestricted use and redistribution provided that the original author and source are credited.

\author{
Ahmed Mokhtar Mahmoud Elbayer*, Habib Al-Basti, Iqbal Wani, Sohail Quazi \\ and Sara Mostafa Mohamed
}

Hamad Medical Corporation, Doha

\begin{abstract}
Comminuted metacarpal fractures are challenging to treat sometimes, especially when there is axial power pushing distal piece proximally which cause shortening of the bone in this work, we will review, an idea to distract the distal piece in order to preserve the length

Keywords: Digit; Digital; Fractures; External; Fixator; Distraction; Complex; Fracture; Joint; Joints; Reduction; Fixation; K wire; K wires; kirschner wire; kirschner wires; Hand; Thumb; Index; Middle; Long; Ring; Little; Metacarpal; Plate; Screws; Prosthesis
\end{abstract}

\section{Introduction}

Metacarpal fractures are very frequent. Treating them mostly can go very well conservatively through splinting 3-6 weeks. In some fractures, surgical intervention is mandatory; when clinically there is shortening or crossing of the fingers or dorsal hump (causes pain +- disfigurement) [1].

\section{Case Presentation}

29-year-old patient sustained trauma to left hand at work, presented 1 month later with extension lag + dorsal tender swelling. X-ray confirms comminuted metacarpal fracture with dorsal displaced bone spike. Surgical intervention is planned through open approach. Upon opening, there were 3-4 fractured pieces with unable to reduce and fix via conventional $1 \mathrm{~mm}$ $\mathrm{K}$ wires because there was pulling forces pushes the distal half proximally which causes significant overlap and shortening of the long finger.

Distraction of the fracture done through placing $\mathrm{T}$ Plate and 4 screws, which showed restoration of the finger length and normal cascade. Placing of $3 \mathrm{k}$ wires done afterwards to fix the small fractured pieces in place. Pre and post op x-rays are shown below.

Early mobility has been started with full restoration of range of movement by 8 weeks (Figure $1 \& 2$ )

\section{Discussion}

Open approach is very important in late surgical intervention to properly reduce "already healed fracture" with removing of the callus formation.

Distraction of the fractured pieces through either plate and screws or External fixator [2] is very important to preserve the length and restore range of movement with zero lag. 


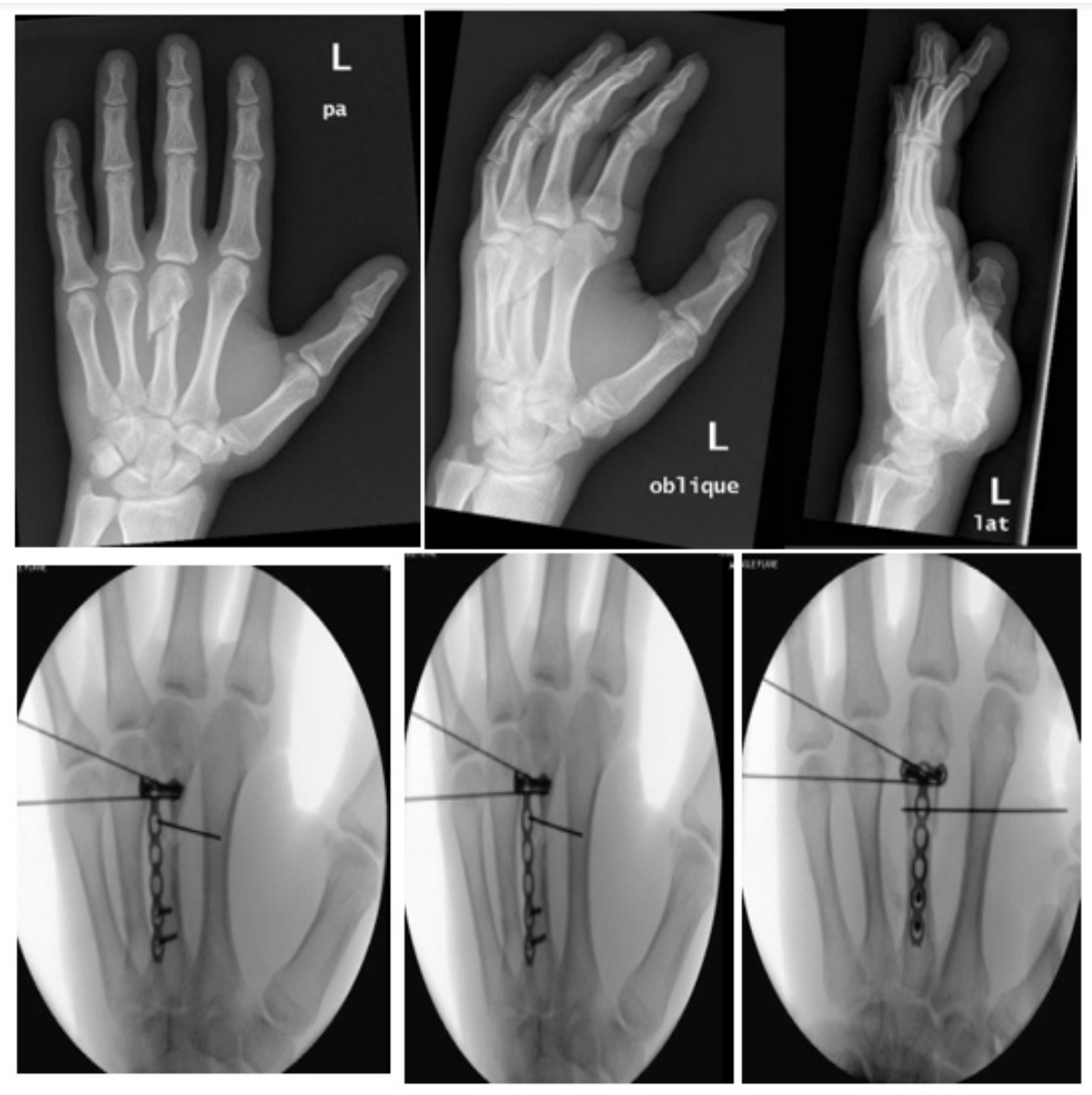

Figure 1: Pre and intra operative pictures (pre and post fixation).
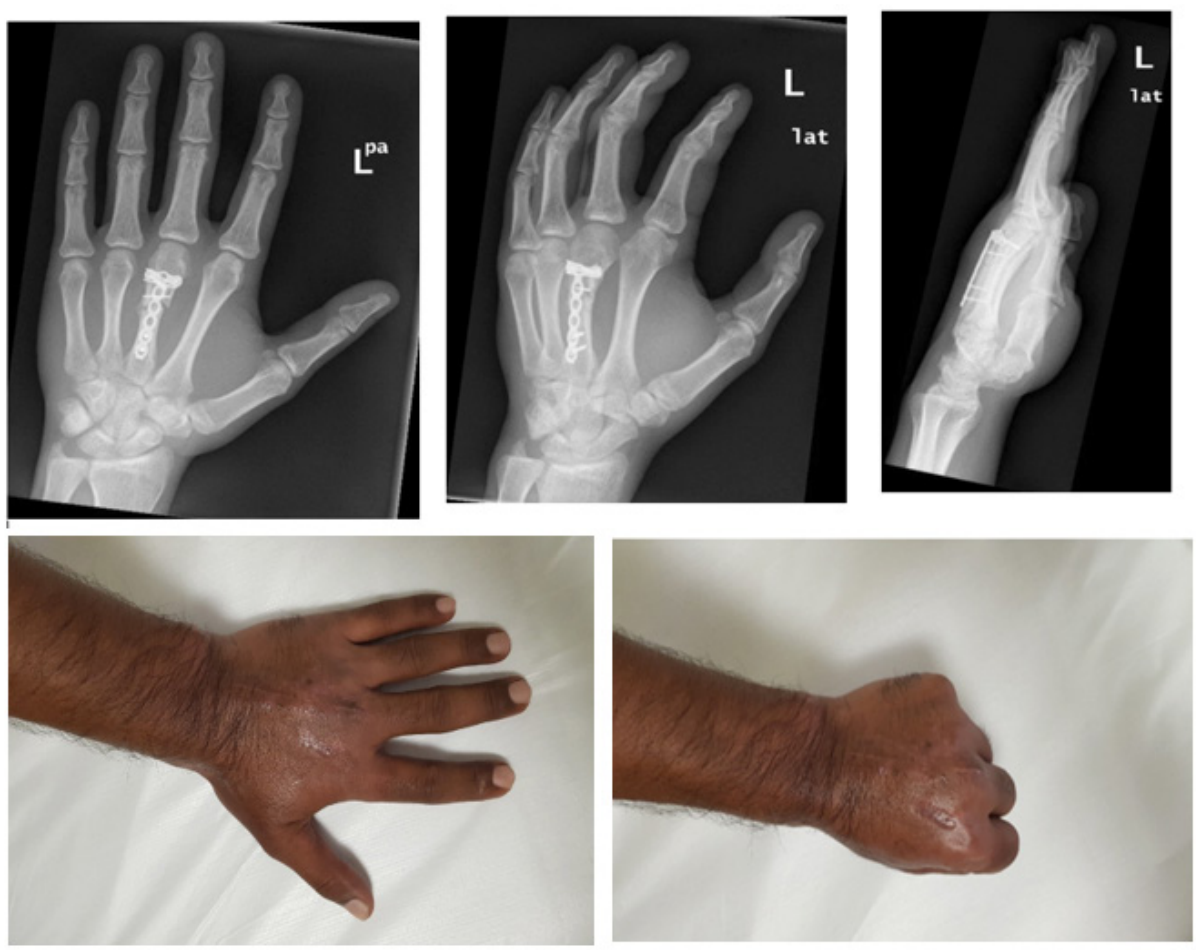

Figure 2: 8 weeks post fixation. 


\section{References}

1. Hastings H (1987) Unstable metacarpal and phalangeal fracture treatment with screws and plates. Clin Orthop Relat Res (214): 37-52.
2. Ahmed MME, Iqbal W, Habib A, Iqbal W, Sohail Q, et al. (2019) External fixator distraction idea to reduce complex digital fractures and preserve digital joints. Ortho Res Online J 5(3): 1-2.

For possible submissions Click below: 